\title{
Efficacy of Dental Mesenchymalstem Cells in Kidney failure
}

\author{
Walaa Fikry Elbossaty* \\ Department of Chemistry, Biochemistry division, Faculty of Science, Damietta University, Damietta, Egypt \\ walaafikry1985@gmail.com
}

\begin{abstract}
Kidney is one of the most important organs in human body; it has various roles in maintenance of life. Any disturbance in composition of kidney may be lead to kidney diseases, so this is reflect on the function of kidney. There are different strategies in treatment of kidney disease. Although, these techniques have useful role in treatment process but also have numerous side effect which not only effect on kidney healthy buteffect on other organs. New trend in treatment process find the way of treatment with out or with few risk. Stem cells use in treatment of different diseases. There are 2 types of stem cells; embryonic stem cells, and adult stem cells;adult stem cells include bone marrow, and teeth stem cells. All researches indicate that stem cell originated from teeth has more efficiency as compared to other types of stem cells. Dental stem cell success in treatment many complicated diseases. In this article we will discuss function of kidney,kidney diseases, stem cells dental stem cells, and its role in treatment of kidney diseases.
\end{abstract}

Key words: Kidney, kidney failure, stem cell, dental stem cell.

\section{INTRODUCTION}

\section{Kidney}

Kidneys are the body's filtering units, which located in the direction of the back of the body, approximately 10 $\mathrm{cm}$ above the hipbones and below the ribcage. Kidney play a vital role in maintaining balance of fluid, minerals, salts and other substances in the blood. They are responsible for removing waste and toxic substances from the body through the urine. In addition to they produce numerous hormones as erythropoietin, which responsible for production of red blood cells; calcitriol, which increase the rate of absorption of calcium and play important role in bone mineralization; and renin, which is enzyme involved in controlling blood pressure Fig.1. [11].

Kidneys are consist from small units which called nephrons, any disturbance in these cells lead to uncontrolling of kidney functions, and development of many kidney diseases. Kidney diseases generally involve damage to the nephrons and can be acute or chronic [12]. In acute kidney disease there is a speedy drop in kidney function. This occurs by loss of large amounts of blood or an accident. While chronic kidney disease (CKD) is well-defined as loss of a third or more of kidney function for at least three months. The risk of developing CKD is increased by age, diabetes, high blood pressure, obesity and smoking. At least $8 \%$ of the people in Europesuffer from CKD, and these people have great risk for developing kidney failure. This risk is increasing every year and there are not enough volunteers to provide transplants for these patients. So most of researchers make all efforts to development of new therapeutic options for treating CKD [8]. 


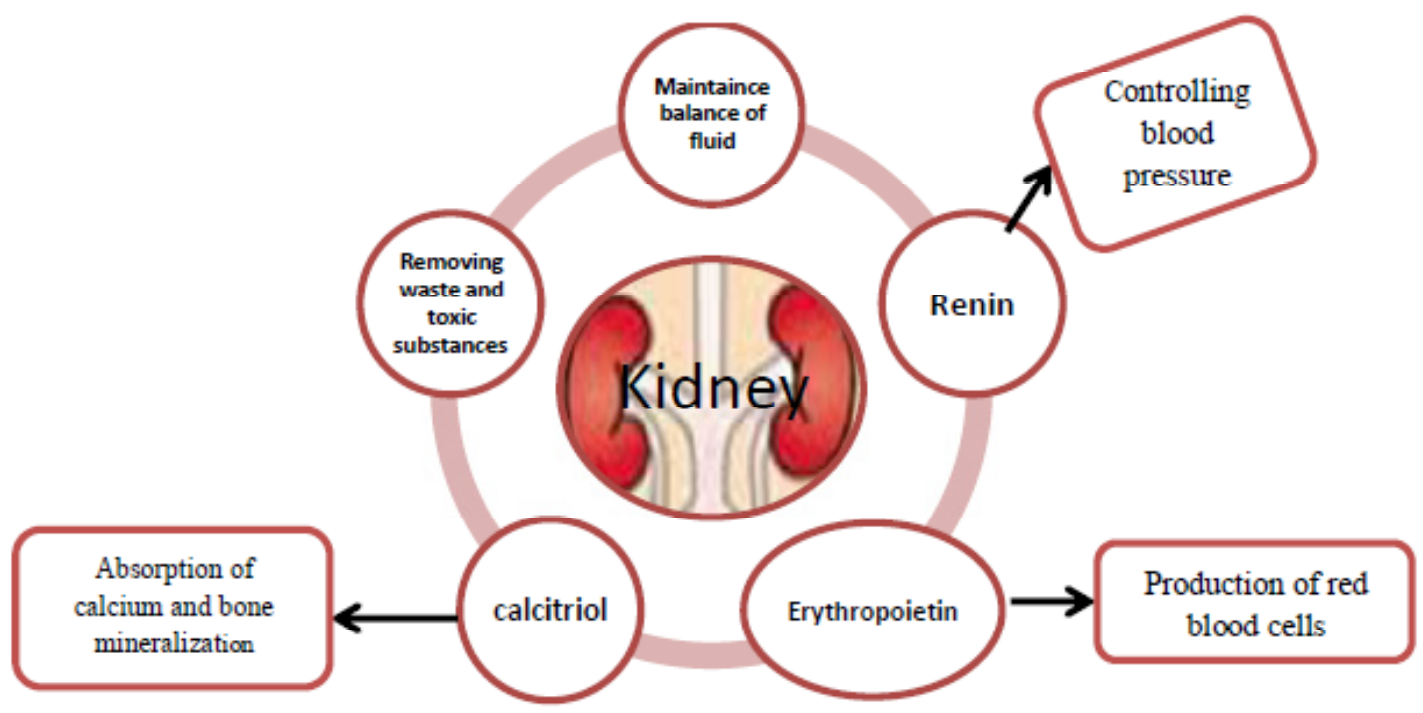

Fig1. Functions of kidney

The chef role of Kidneys is eliminating excess fluids from the blood through urine. Once kidneys start to fail, this function becomes disrupted. More fluids begin collecting in the body. Then, swelling start. Some patients suffer from swollen eyes as well as swollen legs after that the entire body might swells up [9].Variousstudies indicated thatwhen kidney loss its function, it cannot secrete sufficient amount of erythropoietin ,so erythropoietin do not stimulate the bone marrow to produce more red cells , finally anemia will be happens [6].

\section{Stem Cells}

Stem cells are unique for the reason that they drive the natural healing process through your life. Stem cells are unlike other cells in the body since they regenerate and produce specialized cell types. They heal and restore skin, bones, cartilage, muscles, nerves and other tissues once injured. There are two main types of stem cells: adult stem cells, such as those found in bone marrow and teeth,and embryonic stem cells [3].

Nowadays, medical researchers are knowledge how to control stem cells and direct their growth into specialized cells, including: blood, skin, bone, cartilage, teeth, muscle and nerves. This lead to incredible new medical treatments for various difficult diseasesincluding:Parkinson's disease, Brain Injuries, Heart Disease, Diabetes, Arthritis, Muscular dystrophy, Leukemia. Stem cell investigation may also allow utilize the body's own repair mechanisms to discovery treatments for kidney disease. In acute kidney disease, the body can often repair kidney damage itself, on the other hand it is unable to do this well enough in chronic kidney disease. Mesenchymal-stem-cell-like cells in the kidney may open up new possibilities for enhancing the body's own ability for renewal and repair of damaged kidneys [5].

\section{Dental Stem Cell}

Stem cells can be found in most tissues of the body; they are usually hidden deep, few in number and are similar in appearance to surrounding cells. Through the discovery of stem cells in teeth, an available and available source of stem cells has been recognized [7].

The tooth is nature's stem cells; these are abundance in baby teeth, wisdom teeth and permanent teeth. The dental stem cells are capable of replicating themselves so, living stem cells found within extracted teeth; hence we can save these cells for future use in developing medical treatments [4]. 
It is very important in medical treatment using own stem cells due to lower risk of body rejection and decreases the need for drugs which may be weaken the immune system.Several medical research studies indicated that dental stem cells are the most powerful stem cells in the human body. This is due to the ability of dental stem cells to fast and longtime replicate as compared to other stem cells [1].

Dental mesenchymal stem cells are non-hematopoietic, multipotent cells which can proliferate and differentiate into various cell types. These cells characterized with: fibroblast-like morphology, ability to adhere on plastic tissue-culture surfaces, and osteogenic potency. As result of their properties, and easy isolation technique of mesenchymal stem cells, the dental mesechymal stem cells are nowbecome as potential, novel, important tool in treatment of difficult diseases [10].

There are various mesenchymal stem cell be present in the tooth. These are categorized according to their position in the tooth into Fig.2. [14]:

- Dental Pulp Stem Cells, DPSCs

- Periodontal Ligament Stem Cells, PDLSCs

- Dental Follicle Stem Cells, DFSCs

- Stem Cells from the dental Apical Papilla, SCAPs

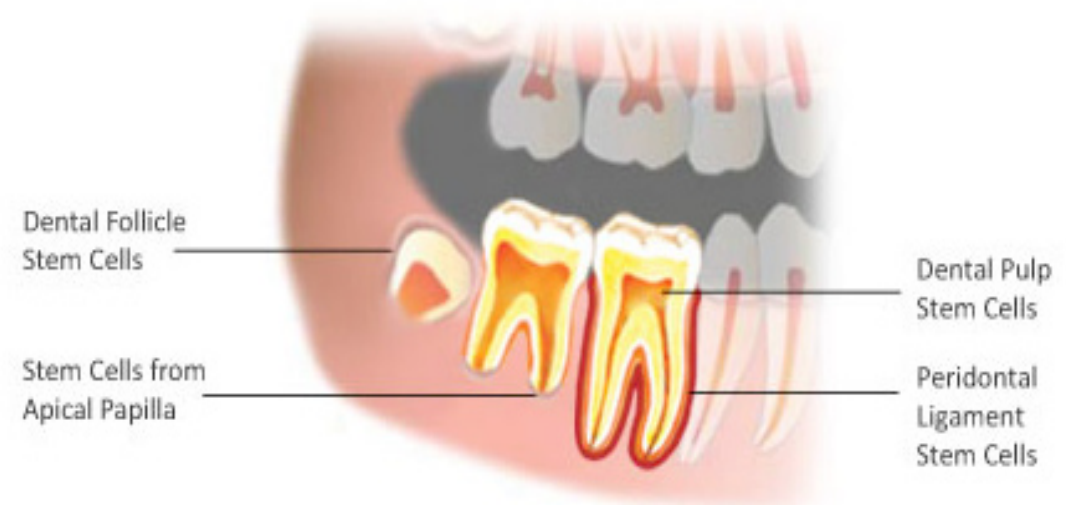

Fig2. Mesenchymal dental stem cell

\section{Management of Kidney Failure by Using Dental Stem Cells}

There are more than 600 clinical trials conducted worldwide to date using mesenchymal dental stem cell (MSC) in treatment of various diseases.Nearly 30 clinical trials of them use MSC to treat kidney diseases. These clinical trials included 3 trials on acute kidney injury; 4 trials on chronic kidney injury; 1 trial on focal segmental glomerulosclerosis; 5 trials on autoimmune disease; and 16 trials on kidney transplantation [13].

Numerous medical researches indicated that administration of MSC has proven significant renoprotective effects including reduction of intrarenal inflammatory infiltrate, decreased fibrosis, and glomerulosclerosis [2].

\section{CONCLUSION}

Dental stem cells have several applications in various medical fields. There are various advantages for dental stem cell as compared to other stem cell types. Mesenchymal dental stem cell have significant effect in treatment of kidney diseases .success of mesenchymal dental stem cell in treatment process open the way for using natural ,available, drugs in treatment of various complicated diseases, this can be help therapists to avoid side effect of chemical therapy, and probability of organ rejection in some cases. 


\section{Conflict of Interest}

The authors declare that they have no Conflict of interest.

\section{REFERENCES}

1. Bae W, Jue S, Kim S, Moon J. "Effects of Sodium Tri- and Hexametaphosphate on Proliferation, Differentiation, and Angiogenic Potential of Human Dental Pulp Cells". Journal of Endodontics.2015; 41 (6): 896-902.

2. Cheng C, Jianquan H. Mesenchymal stem cell-based therapy in kidney transplantation.Stem Cell Res Ther. 2016; 7: 16.

3. Choler H. The Potential of Stem Cells: An Inventory". In Nikolaus Knoepffler; Dagmar Schipanski; Stefan Lorenz Sorgner. Humanbiotechnology as Social Challenge. Ashgate Publishing. p. 28. ISBN 978-0-7546-5755-2.

4. Dannan A. "Dental-derived Stem Cells and whole Tooth Regeneration: an Overview". Journal of Clinical Medicine Research.2009; 1 (2): 63-71.

5. FrancescaG. Extracellular matrix: A dynamic microenvironment for stem cell niche Biochimica et Biophysica Acta (BBA) - General Subjects.2014; 1840(8): 2506-2519

6. Franklin B. Erythropoietin.Cold Spring Harbor Perspectives in Medicine.2017:7(8):1-12

7. Hiroshi E,Ikiru A, Kentaro A. Stem cells in dentistry - Part I: Stem cell sources. Journal of Prosthodontic Research.2012; 56(3):151-165.

8. Michael E,Jussara M, Alexandre A, Luis A. Obesity, hypertension, and chronic kidney disease.Int J Nephrol Renovasc Dis. 2014; 7: 75-88.

9. Moore E, Bellomo R, Nichol A. "The meaning of acute kidney injury and its relevance to intensive care and anaesthesia". Anaesthesia and intensive care. 2012; 40 (6): 929-48.

10. Ramta B, Aditya J. Current overview on dental stem cells applications in regenerative dentistry.J Nat Sci Biol Med. 2015; 6(1): 29-34.

11. Raymond Q. Chronic Kidney Disease: Highlights for the General Pediatrician. International Journal of Pediatrics.2012; 2012(943904):1-5.

12. Rumeyza K. Risk factors for chronic kidney disease: an update.Kidney Int Suppl. 2013; 3(4): 368-371.

13. Xiang-Yang Z, Amir L, Lilach O. Concise Review: Mesenchymal Stem Cell Treatment for Ischemic Kidney Disease. Stem Cells. 2013; 31(9): 1731-1736.

14. Yun-Jong P, Seunghee C, Young-Seok P. Regenerative Applications Using Tooth Derived Stem Cells in Other Than Tooth Regeneration: A Literature Review.Stem Cells Int. 2016; 2016: 9305986.

Citation: Walaa Fikry Elbossaty. "Efficacy of Dental Mesenchymalstem Cells in Kidney failure". American Research Journal of Urology; 2(1): 1-4.

Copyright (C) 2017 Walaa Fikry Elbossaty. This is an open access article distributed under the Creative Commons Attribution License, which permits unrestricted use, distribution, and reproduction in any medium, provided the original work is properly cited. 